\title{
Panta Rhei, the new science decade of IAHS
}

\author{
HUBERT H.G. SAVENIJE ${ }^{1,2}$ \\ 1 Delft University of Technology, PO Box 5048, Delft, The Netherlands \\ 2 President of the International Association of Hydrological Sciences \\ h.h.g.savenije@tudelft.nl
}

\begin{abstract}
To address the water related problems that society is facing in this time and age, hydrologists can no longer consider the hydrological system as if there is no human influence. The human and water systems are closely intertwined and in this interaction patterns emerge that are the result of two co-evolving systems. The hydrology and the water resources form conditions under which societies develop, but as a result, and in turn, societies influence the functioning of the hydrological system. This calls for a new science that tries to understand these interactions with the objective to explore feasible futures and strategies to guide this coevolution towards sustainable use of our natural resources. After the closure of the PUB decade on Prediction in Ungauged Basins, the International Association of Hydrological Sciences (IAHS) has taken up the challenge of trying to make fundamental contributions to this new science of integrated hydrological and societal processes under the title of "Panta Rhei", symbolising that everything changes in a perpetual dynamic interaction between people and water. This may be a big step in the science of hydrology, venturing well outside the comfortable boundaries of pristine hydrology, but the urgency of water issues around the globe forces us to do so, and in the process, hydrologists are likely to discover new paradigms, new modelling approaches, enhanced understanding of the human-water system, and hopefully new ways to steer our society towards a more sustainable future.
\end{abstract}

\section{A NEW SCIENCE AGENDA}

Panta Rhei is the new research agenda of the International Association of Hydrological Sciences

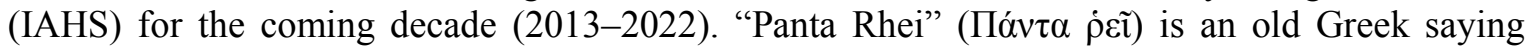
attributed to Heraclitus (BC535-475) meaning "Everything Flows". In a metaphorical sense it means that everything changes continuously, not only the natural system, but also the people living in it. The Panta Rhei initiative aims to enhance our understanding of how people and the hydrological system interact and how they co-evolved under the influence of changing circumstances. This knowledge will help us to better predict probable futures and to make better decisions on interventions for the sustainable management of our natural resources.

Panta Rhei focuses on three themes, or foci: Understanding, Estimation and Prediction, and Science in Practice. The first focus aims at furthering our understanding of how people and the natural system co-evolved and what feedback mechanisms are driving co-evolution. The second focus aims at applying this understanding in models that can be used to predict development and to explore feasible future scenarios with their related uncertainties. The third focus aims at making this information useful for society and to develop applications that can be used in practice. For details about Panta Rhei, please see the paper on Panta Rhei by Montanari et al. (2013).

\section{People are central}

The metaphor of Panta Rhei is the well-known observation by Heraclitus that "no person can step into the same river twice, because at the second time the river has changed and also the person is no longer the same". The beauty of this metaphor is that it involves both people and water and it is a perfect illustration of the fact that we can only understand change if we understand how people and water interact.

From the moment Homo sapiens entered the global scenery, people and water have always interacted, and probably even before that. We now have started to call the geological period where there is a noticeable influence of people the 'Anthropocene', after Crutzen (2002). There is some debate about when the Anthropocene started, but one of the first activities humans undertook to modify the landscape was to tap water from the natural system: designing wells, diverting river water, harvesting rainwater, tapping groundwater by underground tunnels (qanats), and building canals and aquaducts to convey water to where it was needed. Although these are sometimes 
highly complex engineering works, it was only a first step towards manipulating the natural system. In guaranteeing access to water, people soon realized that it was necessary to create sufficient storage to offset the high variability of hydrological fluxes in the natural system. The building of reservoirs dates back as far as 5000 years before present, when the first reservoir was built in the Middle East, not surprisingly in an area with high hydrological variability. Since then people have continuously responded to environmental pressures and adjusted their management of natural resources to climatic drivers. Learning from their mistakes, societies adjusted their interventions in a continuous feedback with the natural environment. In recent years these developments have accelerated such that it is no longer possible to study the natural system and the human system in isolation, or even in parallel as loosely coupled systems. The only way to explore feasible developments is by a close coupling between society and the natural environment.

A nice example of a study that aimed at understanding how society and the natural system influence each other is given in the recent paper by Van Emmerik et al. (2014). Through the use of a dynamic system model, that includes societal as well as natural processes, it explains the impressive 'pendulum swing' between agricultural development and environmental restoration that occurred in the Murrumbidgee River basin in Australia. In the paper, similar to other theoretical exercises, such as by Di Baldassarre et al. (2013), a dynamic systems analysis model is used that incorporates all thinkable impacts and feedbacks between a wide variety of system states, such as: hydrology, ecology, economy, population, environmental awareness, human settlement, and urban and agricultural development. Of course one may doubt the level of realism of such exercises, but these models are not intended to correctly simulate what happened or what will happen. Rather they are investigative tools to study the interactions and feedbacks between system states, to explore consistent possible futures, and to investigate to which (multiple) stable states these would potentially lead. In short, they help us to lift a corner of the curtain and to peek into the future to see where the world might possibly take us. But more importantly, it will help us to better understand how we interact with the natural system.

This is an essential new research focus. For too long, we, hydrologists, have focused on pristine catchments or studied catchments that were "as natural as possible", whereas society wanted us to inform them of the impact we have on the system.

\section{But is this also important for hydrology itself?}

I think that it is not hard to convince the hydrological community that Panta Rhei is a timely and necessary new research focus, but I can also imagine that there are many hydrologists who fear that Panta Rhei will divert our attention from pure hydrological work, where there still is so much to discover. We have just completed the decade on Prediction in Ungauged Basins (Hrachowitz et al. 2013) and we all know that our knowledge of hydrology is still far from perfect. There are still many challenges and unanswered questions, some of them very old. I often freely quote Jim Dooge, who saw hydrology as a complex system with some form of organisation. He was surprised that such an obviously complex system could sometimes manifest such treacherously simple and predictable behaviour (Dooge 1997). It is one thing to notice this remarkable simplicity, but understanding why nature often manifests itself in simple and predictable equations is another. Yet, this simplicity is an essential characteristic of the science of hydrology.

\section{Emerging patterns}

The hydrological system is driven by gradients, which drive water to circulate through the Earth's system. We know that gradients induce fluxes through media and that in the process patterns occur. Just look at the patterns in the landscape, or at the veins in leaves, or in our bodies. Gradients lead to fluxes and fluxes lead to patterns, and these patterns determine the flows and the gradients in continuous feedback loops. Rodríguez-Iturbe and Rinaldo (2001) wrote a standard work about patterns in the landscape, but obviously, similar patterns are present below ground, both in the unsaturated zone of hillslopes and in the groundwater. Yet we have not even begun to explore the characteristics of these patterns at the catchment scale, which probably holds the key to 
understanding why simple mathematical models, such as the linear reservoir, apply to so many cases in hydrology.

Impressive work by Axel Kleidon and co-authors linked Maximum Entropy Production to erosion processes (Kleidon et al. 2013) and to evaporation (Kleidon and Renner 2013). In the latter, the authors derived a strikingly simple global evaporation equation from basic principles, which they tested against data (Kleidon et al. 2014). This is very important work that demonstrates that simplicity is a property of natural systems that emerges as a result of fundamental physical laws. So using simple equations is nothing to be ashamed of, because they often are truly physically based. The challenge is to provide this physical basis. And this is where Panta Rhei can help. As Kleidon showed, patterns emerge through mutual feedback between processes, searching for an optimum at the Carnot maximum power limit. It is no different in Panta Rhei. We try to increase our understanding of complex process interactions between people and the natural system, but in developing tools to do this we also contribute to the older targets of PUB.

I recently was part of such an effort myself. By studying the interaction between climate, ecosystem and soil, we found that the root zone storage capacity of ecosystems is essentially a buffer that the ecosystem created to bridge critical periods of drought. By assuming that ecosystems adjust this buffer to the variability of the climate, we were able to predict one of the most important regulators of the hydrological system and a key parameter in hydrological models: the maximum dynamic storage capacity in the unsaturated zone (Gao et al. 2014). So it is my conviction that this new focus on co-evolution, so crucial in Panta Rhei, will also be very important for PUB, for hydrology as an Earth science, and, not least, for hydrology in practice.

\section{GOING BEYOND THE TRADITIONAL LIMITS OF HYDROLOGY}

How to do this? This may well be an almost impossible question to answer. But "impossible questions", as Keith Beven remarked during the PUB closing symposium in Delft in 2012, are perfect to guide innovations and the creativity of a scientific community, even if they do not result in clear-cut answers. We realize that addressing these questions can only be done if we approach them from a multi-disciplinary angle, involving natural sciences, social sciences and their subdisciplines, e.g. ecology, history, archaeology, physical geography and economics, to name just a few. Also, if we want to understand our future, we will have to start understanding our history, particularly the way in which people interacted with and responded to the dynamics of the natural environment, and how this in turn changed the dynamics of the natural system.

\section{REFERENCES}

Crutzen, P. (2002) Geology of mankind. Nature 415, 23 (3 January 2002).

Di Baldassarre, G., et al. (2013) Socio-hydrology: conceptualising human-flood interactions. Hydrol. Earth Syst. Sci. 17, 3295-3303.

Dooge, J.C.I. (1997) Searching for simplicity in hydrology. Surveys in Geophysics 18(5), 511-534

Gao, H., et al. (2014) Climate controls how ecosystems size the root zone storage capacity at catchment scale. Geophysical Research Letters, 41, 7916-7923, doi:10.1002/2014GL061668

Hrachowitz, M., et al. (2013) A decade of Predictions in Ungauged Basins (PUB) - a review. Hydrological Sciences Journal 58(6), 1-58.

Kleidon, A. and Renner, M. (2013) Thermodynamic limits of hydrologic cycling within the Earth system: concepts, estimates and implications. Hydrol. Earth Syst. Sci. 17, 2873-2892.

Kleidon, A., et al. (2013) Thermodynamics, maximum power, and the dynamics of preferential river flow structures at the continental scale. Hydrol. Earth Syst. Sci. 17, 225-251.

Kleidon, A., Renner, M., and Porada, P. (2014) Estimates of the climatological land surface energy and water balance derived from maximum convective power. Hydrol. Earth Syst. Sci. 18, 2201-2218.

Montanari, A., et al. (2013) "Panta Rhei, Everything Flows": Change in hydrology and society; The IAHS Scientific Decade 2013-2022. Hydrological Sciences Journal 58(6), doi:10.1080/02626667.2013.809088.

Rodríguez-Iturbe, I. and Rinaldo, A. (2001) Fractal River Basins: Chance and Self-Organization. Cambridge University Press.

Van Emmerik, T. H. M. et al. (2014) Socio-hydrologic modeling to understand and mediate the competition for water between agriculture development and environmental health: Murrumbidgee River basin, Australia. Hydrol. Earth Syst. Sci. 18, 4239-4259. 